\title{
Aspectos Qualitativos da Carcaça e da Carne de Machos Hereford, Inteiros ou Castrados, Abatidos aos Quatorze Meses
}

\author{
Fabiano Nunes Vaz'1, João Restle ${ }^{2}$
}

\begin{abstract}
RESUMO - Com o objetivo de estudar as características qualitativas da carcaça e da carne de machos inteiros ou castrados, abatidos aos quatorze meses de idade, foram utilizados quinze machos Hereford, sendo oito castrados aos sete meses e sete mantidos inteiros. Os animais foram criados do nascimento até o desmame em campo nativo melhorado e, após o desmame, aos sete meses, foram confinados até o abate. As avaliações da carne foram realizadas no músculo Longissimus dorsi e, para a determinação da composição da carcaça, foi utilizada a técnica da separação física de músculo, gordura e osso. Os animais castrados apresentaram carcaças com maior teor de gordura ( 24,89 contra $19,89 \%)$ e carne de melhor coloração (4,37 contra 2,85 pontos), enquanto os inteiros apresentaram maior percentagem de músculo na carcaça $(65,38$ contra $60,48 \%)$, menor quebra ao descongelamento (3,29 contra 7,48\%), carne mais macia, medida pelo painel de degustadores (7,93 contra 6,60 pontos), e de melhor palatabilidade que os castrados (6,40 contra 5,52 pontos). As análises de correlação dentro do grupo de animais inteiros mostraram que a maior maciez da carne de animais inteiros pode ter sido em função da carne destes ter atingido o estado "EFS" ("escura, firme e seca"), pois a correlação da maciez da carne com a cor foi de -0,93 e, com a perda ao descongelamento, de - 0,88 . Os resultados mostram que, em idade jovem, machos inteiros podem ser utilizados para a produção de carne, sem prejuízo na qualidade.
\end{abstract}

Palavras-chave: bos taurus, castração, cor da carne, maciez, marmoreio

\section{Qualitative Aspects of the Carcass and Meat of Hereford Males, Entire or Castrated, Slaughtered at Fourteen Months of Age}

\begin{abstract}
With the objective to study the carcass and the meat qualitative characteristics of young bulls or castrated males, slaughtered at fourteen months of age, fifteen Hereford males were used, eight castrated at seven months and seven kept entire. From birth to weaning animals were raised on improved native pasture, and after weaning, at seven months, they were confined. Meat measurements were taken from the longissimus muscle, and to determine carcass composition the method of manual dissection of muscle, fat and bone, was used. Castrated males showed carcasses with higher fat percentage (24.89 vs. $19.89 \%)$ and better meat color ( 4.37 vs. 2.85 points). The young bulls showed carcasses with higher muscle percentage (65.38 vs. $60.48 \%)$, and meat with smaller thawing losses (3.29 vs. $7.48 \%$ ), higher tenderness when measured by the taste panel (7.93 vs. 6.60 points), and of better flavor ( $6.40 \mathrm{vs.} 5.52$ points) as compared to the castrated males. Correlation analysis within the young bulls showed that the highest meat tenderness of the young bulls might have been a result of "DFD" (dark, firm and dry) condition, since the correlation between tenderness and meat color was -.93, and tenderness and thawing losses was -.88 . The results show that, in young age, bulls can be used to produce meat without reducing its quality.
\end{abstract}

Key Words: bos taurus, castration, meat color, marbling, tenderness

\section{Introdução}

A castração dos machos foi um manejo tradicionalmente usado pelos produtores de bovinos de corte, visando evitar o efeito dos hormônios androgênicos sobre as características de carcaça e da carne (RESTLE et al., 1999b), pois animais inteiros apresentam carcaça mais magra, carne mais escura, mais dura e de pior palatabilidade que os castrados (MULLER e RESTLE, 1983; RESTLE et al., 1994, RESTLE et al., 1996a).

Entretanto, vários trabalhos têm demonstrado que esses mesmos hormônios são responsáveis por maior velocidade de crescimento e melhor conversão alimentar dos animais inteiros em relação aos castrados (RESTLE et al., 1996b; RESTLE et al., 1997).

A terminação de animais com idade variando entre 12 e 15 meses vem sendo cada vez mais utilizada pelos produtores. Esta prática, além de aumentar o desfrute do rebanho e o giro de capital, propicia o retorno do crescimento do consumo da carne bovina (VAZ et al., 1999b), pois é incontestável a melhor qualidade desse produto, quando é originária de animais abatidos com aproximadamente 
um ano de idade (RESTLE et al., 1999a).

Tendo em vista que o efeito dos hormônios androgênicos sobre as características de carcaça e da carne é mais marcante em animais abatidos em idade mais avançada (RESTLE et al., 1994; RESTLE e VAZ, 1997), é necessário, nas nossas condições, maiores estudos sobre o efeito da não-castração dos machos nas características qualitativas da carcaça e da carne de animais jovens.

O objetivo deste trabalho foi estudar o efeito da não-castração dos machos sobre as características qualitativas da carcaça e da carne de animais abatidos aos quatorze meses de idade.

\section{Material e Métodos}

Este trabalho foi conduzido no Setor de Bovinocultura de Corte do Departamento de Zootecnia da Universidade Federal de Santa Maria (UFSM), localizada no município de Santa Maria, RS.

Foram utilizados 15 bezerros Hereford, tomados ao acaso de um rebanho de uma propriedade particular, localizada no município de Dom Pedrito, RS. Os animais foram mantidos ao pé da vaca, em campo nativo melhorado até os sete meses de idade, quando foram desmamados e distribuídos aleatoriamente em dois tratamentos: animais castrados à faca (C), e animais mantidos inteiros (I). Após o desmame e castração dos animais do grupo $\mathrm{C}$, os 15 animais foram levados para o confinamento, pesando em média $164 \mathrm{~kg}$, onde permaneceram até os 14 meses de idade, quando foram abatidos.

Durante o período de confinamento, foi fornecida uma ração contendo $12 \%$ de proteína bruta e a proporção média de volumoso/concentrado foi de 54/46 (base da matéria seca). Utilizaram-se silagem de sorgo forrageiro, como volumoso, e concentrado à base de grão de milho triturado, farelo de arroz desengordurado, farelo de soja, farinha de carne e minerais.

$\mathrm{O}$ abate dos animais foi realizado em abatedouro comercial, seguindo-se o fluxo normal do estabelecimento. Após o resfriamento das carcaças por 24 horas a $0^{\circ} \mathrm{C}$, foi medido o $\mathrm{pH}$ das carcaças e avaliada a maturidade fisiológica das mesmas, segundo a técnica descrita por MULLER (1987).

Na meia-carcaça direita, foi realizado um corte na altura da $12^{\mathrm{a}}$ costela, na qual, após a exposição do corte por 20 minutos, para a oxigenação da mioglobina, foi avaliada a coloração da carne, seguindo-se uma escala de 1 a 5 pontos, em que o maior valor represen- ta uma carne de coloração vermelha clara brilhante e o menor valor, coloração vermelha muito escura (MULLER, 1987). No mesmo corte, foram avaliados o marmoreio, utilizando-se uma escala de 1 a 18 pontos, em que os pontos crescem à medida que aumenta a quantidade de marmoreio, e a textura, utilizando-se uma escala de 1 a 5 pontos, na qual o valor mais alto indica uma textura mais fina (MULLER, 1987).

Para a determinação da composição física da carcaça, foi extraída uma amostra localizada entre a 10 e $12^{\mathrm{a}}$ costela da meia-carcaça direita. Essa amostra foi dissecada, por meio da separação física de músculo, gordura e osso, conforme os procedimentos sugeridos por MULLER (1987). A porção do músculo longissimus dorsi, extraída dessa peça, foi embalada, identificada e congelada. Após o congelamento, foram extraídas, de cada amostra, duas fatias (fatias A e B) de $2,5 \mathrm{~cm}$ e uma de $0,5 \mathrm{~cm}$ de espessura (fatia $C$ ), todas obtidas perpendicularmente ao comprimento do músculo.

Para cálculo das perdas ao descongelamento e cocção, foi realizada a pesagem da fatia $\mathrm{B}$, ainda congelada, depois de descongelada (antes de ser levada ao forno) e após o cozimento, que aconteceu até que a temperatura interna da fatia atingisse $70^{\circ} \mathrm{C}$. A pesagem após o cozimento foi realizada após a fatia voltar à temperatura ambiente. Após o cozimento e a pesagem da fatia, foram extraídas três amostras de feixes de fibras, circulares, com $1 \mathrm{~cm}^{2}$ de área, as quais foram cortadas perpendicularmente à fibra, por intermédio do aparelho Warner-Bratzler Shear, que mede a resistência das fibras ao corte.

A fatia A foi descongelada e cozida juntamente com a fatia B e, após a cocção, foi distribuída, da fatia A, uma porção de $2 \times 2 \mathrm{~cm}$ para cada um dos quatro avaliadores, os quais foram previamente treinados para atribuir valores de 1 a 9 para as características maciez, suculência e palatabilidade da carne. A fatia $\mathrm{C}$ foi utilizada para determinação do teor de colágeno total do músculo.

O delineamento experimental foi o inteiramente casualizado, com número diferente de repetições, sendo utilizado o seguinte modelo estatístico:

$$
\mathrm{Y}_{\mathrm{ijk}}=\mu+\mathrm{ES}_{\mathrm{i}}+\mathrm{e}_{\mathrm{ijk}}
$$

em que $Y_{i j}$ representa a observação realizada no nésimo animal, pertencente ao i-ésimo estado sexual; $\mu$, a média geral da característica; $\mathrm{ES}_{\mathrm{i}}$, o efeito do iésimo estado sexual; $\mathrm{e}_{\mathrm{ij}}$, o efeito residual realizada no n-ésimo animal.

Os dados foram submetidos às análises de variância e correlação. 


\section{Resultados e Discussão}

Na Tabela 1 são apresentados os resultados da análise de variância para todas as características dependentes estudadas.

Observa-se na Tabela 2 que não houve diferença significativa para a maturidade fisiológica das carcaças $(\mathrm{P}>0,573)$. A cor da carne foi mais clara $(\mathrm{P}<0,037)$ nos animais $C(4,37$ pontos) em relação aos $\mathrm{I}(2,85$ pontos). Carne mais clara em animais $\mathrm{C}$ também foi reportada nos trabalhos de MULLER e RESTLE (1983) e VAZ et al. (1999a).

Não se observou diferença significativa entre os estados sexuais para as características textura $(\mathrm{P}>0,234)$ e marmoreio da carne $(\mathrm{P}>0,062)$, embora os animais I tenham mostrado marmoreio classificado como leve menos ( 3,28 pontos) e os animais $\mathrm{C}$ marmoreio leve mais ( 6,00 pontos).

Ainda na Tabela 2, analisando-se a composição física da carcaça, observa-se que os dois estados sexuais diferiram no percentual de músculo, que foi maior nos animais I $(65,38$ contra $60,48 \%)$, e no percentual de gordura da carcaça, que foi maior nos animais C $(24,89$ contra $19,89 \%)$. Carcaças mais magras em animais I foram citadas nos trabalhos de MULLER e RESTLE (1983), RESTLE et al. (1994), RESTLE et al. (1996a) e VAZ et al. (1999a).

Não houve diferença no percentual de ossos da carcaça. O maior percentual de músculo na carcaça dos animais I não foi suficiente para propiciar maior relação músculo/osso da carcaça destes em relação aos $\mathrm{C}(\mathrm{P}>0,166)$. Também a relação músculo + gordura/osso, que representa a porção comestível da carcaça em relação à quantidade de ossos, não foi significativamente diferente $(\mathrm{P}>0,619)$ entre os dois estados sexuais.

$\mathrm{Na}$ Tabela 3, são apresentados os resultados referentes às características de quebra ao descongelamento e cocção, características sensoriais, força para o corte das fibras e teor de colágeno total no músculo Longissimus dorsi.

Ao se analisarem as quebras apresentada pela carne durante o descongelamento e a cocção, observa-se que animais $\mathrm{C}$ mostraram quebra ao descongelamento significativamente maior $(\mathrm{P}<0,001)$ que os I, 7,48\% nos C e 3,29\% nos I. A quebra à cocção não diferiu entre os dois grupos de animais $(\mathrm{P}>0,062)$.

MULLER e ROBAINA (1981), em seu trabalho, utilizaram novilhos de raças britânicas agrupados por idade e grau de acabamento, e alertam que, quando o objetivo é melhorar as características sensoriais da carne e diminuir as perdas ao descongelamento e cocção, não basta somente que o animal seja jovem, mas também que possua bom acabamento e marmoreio. No presente trabalho, embora os animais I tenham mostrado carcaças mais magras (Tabela 2), somando-se as quebras ao descongelamento e à cocção, os animais I perderam $26,61 \%$, desde o descongelamento até o final da cocção, enquanto os animais $\mathrm{C}$ perderam $36,22 \%$ (Tabela 3 ).

Também a maciez da carne foi maior nos animais I $(\mathrm{P}<0,05)$, pois na avaliação realizada pelo painel de degustadores, os animais I receberam a classificação "muito macia" ( 7,93 pontos), enquanto para os animais C a classificação se situou entre "levemente acima da média"e "macia" (6,60 pontos). Entretanto, ao se medir a força necessária para o corte das fibras, por meio do aparelho WB Shear, a diferença foi numérica $(4,56$ contra 6,12 kg), mas não-significativa $(\mathrm{P}>0,092)$.

Em uma revisão sobre animais I e C, FIELD (1971) relatou que não são comuns os trabalhos que mostram carne mais macia em animais inteiros, entretanto alerta que isso pode ser em função de idades de abate tardias, pois animais não-castrados apresentam maturidade fisiológica mais avançada, e, com o aumento da maturidade fisiológica, cresce o conteúdo de colágeno no músculo, diminuindo a maciez da carne. No presente estudo, observa-se que não houve diferença na maturidade fisiológica entre os dois grupos de carcaças (Tabela 2).

Revisando os trabalhos que compararam animais I e $\mathrm{C}$ abatidos em idades jovens, não se verificou diferença na maciez entre esses dois estados sexuais, quando o abate ocorre aos 18 (HEDRICK et al., 1969) ou 16 meses de idade (SEIDEMAN et al., 1982).

Também se pode somar a isso a teoria apresentada no trabalho de VAZ et al. (1999a), os quais explicam que a maior maciez da carne apresentada por animais I pode ser oriunda da condição de maior estresse préabate destes animais em relação aos C. Segundo FELÍCIO (1993), animais inteiros são mais susceptíveis a apresentar carne "DFD" ("dark, firm and dry", ou seja, escura, consistente e pouco exsudativa). LAWRIE (1970) relatou que carnes tipo "DFD", com $\mathrm{pH}$ acima de 5,8, costumam ser mais macias que as normais. O declínio do $\mathrm{pH}$ está intimamente ligado com o metabolismo de glicogênio, portanto, músculos que perdem reservas de glicogênio durante a condição de estresse pré-abate apresentam suprimento inicial de energia pequeno, diminuindo a formação de ácido lático e, conseqüentemente, impedindo que $\mathrm{opH}$ 
VAZ e RESTLE

Tabela 1 - Quadrados médios das análises de variância e teste F, para as características de qualidade da carcaça e da carne de bovinos Hereford inteiros ou castrados, abatidos aos 14 meses

Table 1 - Mean squares of the analysis of variance and $F$ test, for carcass and meat quality characterisitcs of Hereford males, bulls or castrated, slaughtered at 14 months

\begin{tabular}{|c|c|c|c|c|c|c|c|}
\hline \multirow[t]{2}{*}{$\begin{array}{l}\text { Característica } \\
\text { Characteristic }\end{array}$} & \multicolumn{2}{|c|}{$\begin{array}{l}\text { Graus de liberdade } \\
\text { Degrees of freedom }\end{array}$} & \multicolumn{2}{|c|}{$\begin{array}{l}\text { Quadrado médio } \\
\text { Means squares }\end{array}$} & \multirow[t]{2}{*}{$\begin{array}{l}\text { Teste } \mathrm{F} \\
F \text { value }\end{array}$} & \multirow[t]{2}{*}{$\begin{array}{l}\mathrm{P}>\mathrm{F} \\
P>F\end{array}$} & \multirow[t]{2}{*}{$\begin{array}{c}\mathrm{r}^{2} \\
R \text {-square }\end{array}$} \\
\hline & $\begin{array}{l}\text { Modelo } \\
\text { Model }\end{array}$ & $\begin{array}{l}\text { Erro } \\
\text { Error }\end{array}$ & $\begin{array}{l}\text { Modelo } \\
\text { Model }\end{array}$ & $\begin{array}{l}\text { Erro } \\
\text { Error }\end{array}$ & & & \\
\hline $\begin{array}{l}\text { Maturidade fisiológica } \\
\text { Phvsiologic maturity }\end{array}$ & 1 & 13 & 0,144 & 0,430 & 0,34 & 0,573 & 0,025 \\
\hline $\begin{array}{l}\text { Cor } \\
\text { Meat color }\end{array}$ & 1 & 13 & 8,601 & 1,595 & 5,39 & 0,037 & 0,293 \\
\hline $\begin{array}{l}\text { Textura } \\
\text { Texture }\end{array}$ & 1 & 13 & 1,543 & 0,989 & 1,56 & 0,234 & 0,107 \\
\hline $\begin{array}{l}\text { Marmoreio } \\
\text { Marbling }\end{array}$ & 1 & 13 & 27,50 & 6,57 & 4,19 & 0,061 & 0,244 \\
\hline $\begin{array}{l}\mathrm{pH} \text { da carcaça fria } \\
\text { Cold carcass } \mathrm{pH}\end{array}$ & 1 & 13 & 1,852 & 0,112 & 16,55 & 0,001 & 0,560 \\
\hline $\begin{array}{l}\text { Percentagem de músculo } \\
\text { Muscle percentage }\end{array}$ & 1 & 13 & 89,82 & 6,88 & 13,05 & 0,003 & 0,501 \\
\hline $\begin{array}{l}\text { Percentagem de osso } \\
\text { Bone percentage }\end{array}$ & 1 & 13 & 0,221 & 0,673 & 0,33 & 0,577 & 0,025 \\
\hline $\begin{array}{l}\text { Percentagem de gordura } \\
\text { Fatpercentage }\end{array}$ & 1 & 13 & 93,44 & 5,30 & 17,65 & 0,001 & 0,576 \\
\hline $\begin{array}{l}\text { Relação músculo/osso } \\
\text { Muscle/bone relation }\end{array}$ & 1 & 13 & 0,249 & 0,116 & 2,15 & 0,166 & 0,142 \\
\hline $\begin{array}{l}\text { Rel. músc.+gord./osso } \\
\text { Muscle+fat/bone relation }\end{array}$ & 1 & 13 & 0,039 & 0,150 & 0,26 & 0,619 & 0,020 \\
\hline $\begin{array}{l}\text { Perda ao descongelar } \\
\text { Thawing loss }\end{array}$ & 1 & 13 & 78,48 & 4,54 & 17,29 & 0,571 & 0,001 \\
\hline $\begin{array}{l}\text { Perda à cocção } \\
\text { Cooking loss }\end{array}$ & 1 & 13 & 90,19 & 21,69 & 4,16 & 0,242 & 0,062 \\
\hline $\begin{array}{l}\text { Maciez } \\
\text { Tenderness }\end{array}$ & 1 & 13 & 6,540 & 1,304 & 5,02 & 0,278 & 0,043 \\
\hline $\begin{array}{l}\text { Suculência } \\
\text { Juiciness }\end{array}$ & 1 & 13 & 4,147 & 1,788 & 2,32 & 0,151 & 0,152 \\
\hline $\begin{array}{l}\text { Palatabilidade } \\
\text { Palatability }\end{array}$ & 1 & 13 & 2,935 & 0,552 & 5,31 & 0,290 & 0,038 \\
\hline $\begin{array}{l}\text { Força de cizalhamento } \\
\text { WB-Shearforce }\end{array}$ & 1 & 13 & 9,165 & 2,769 & 3,31 & 0,203 & 0,092 \\
\hline $\begin{array}{l}\text { Colágeno total } \\
\text { Total collagen }\end{array}$ & 1 & 13 & 0,755 & 0,485 & 1,56 & 0,234 & 0,107 \\
\hline
\end{tabular}

decresça normalmente (JUDGE et al., 1989).

Observa-se, na Tabela 2, que no presente trabalho o $\mathrm{pH}$ das carcaças dos animais I situou-se acima de $5,8(6,21)$ e foi maior $(\mathrm{P}<0,001)$ do que nas carcaças dos C (5,51). Segundo DRANSFIELD (1994), a intensidade de declínio do $\mathrm{pH}$ é um dos fatores mais importantes no processo de amaciamento da carne pós-abate, pois alteram a estrutura do músculo, a liberação de cálcio e a atividade das enzimas cálciodependentes.

$\mathrm{Na}$ Tabela 4, são apresentados os coeficientes de correlação entre as variáveis medidas nos animais I.

Observa-se que realmente a correlação foi negativa e alta entre coloração da carne e maciez $(\mathrm{r}=-0,93 ; \mathrm{P}<0,01)$, ou seja, à medida que a coloração apresentou valores mais baixos (mais escura), aumentou a maciez da carne. A correlação entre maciez e perda ao descongelamento também foi negativa e alta $(\mathrm{r}=-0,88 ; \mathrm{P}<0,01)$, ou seja, as carnes com maiores valores para maciez foram aquelas que apresentaram menores perdas ao descongelamento, portanto carnes pouco exsudativas. Também a correlação entre os valores de Shear e perda ao descongelamento foram altas e significativas, entretanto positivas, pois os valores de Shear foram maiores, à medida que aumentou a resistência das fibras ao corte.

A teoria de que a carne dos animais inteiros tem apresentado estado "DFD" é melhor aceita, quando se observa que não houve correlação significativa entre maciez e cor $(\mathrm{r}=0,47 ; \mathrm{P}>0,237)$ e entre maciez e perda 
1898 Rev. bras. zootec.

Tabela 2 - Média e erro-padrão (EP) para maturidade fisiológica, cor, textura, marmoreio, pH da carcaça fria, percentagem de músculo, gordura e osso e relação músculo/osso e músculo+gordura/osso, de machos Hereford, inteiros ou castrados, abatidos aos 14 meses

Table 2 - Mean and standard error (SE) for physiologic maturity, meat color, texture, marbling, cold carcass pH, muscle, fat and bone percentages, muscle/bone relation and muscle+fat/bone relation of Hereford males, bulls or castrated, slaughtered at 14 months

\begin{tabular}{|c|c|c|c|c|c|c|}
\hline \multirow[t]{2}{*}{$\begin{array}{l}\text { Característica } \\
\text { Characteristic }\end{array}$} & \multicolumn{2}{|c|}{$\begin{array}{c}\text { Inteiros } \\
\text { Bulls } \\
\end{array}$} & \multicolumn{2}{|c|}{$\begin{array}{l}\text { Castrados } \\
\text { Castrated }\end{array}$} & \multirow[t]{2}{*}{$\mathrm{CV}(\%)^{1}$} & \multirow[t]{2}{*}{$\begin{array}{c}\text { Probabilidade } \\
\text { Probability }\end{array}$} \\
\hline & $\begin{array}{c}\text { Média } \\
\text { Mean }\end{array}$ & $\begin{array}{l}\mathrm{EP} \\
S E \\
\end{array}$ & $\begin{array}{c}\text { Média } \\
\text { Mean }\end{array}$ & $\begin{array}{l}\mathrm{EP} \\
S E\end{array}$ & & \\
\hline $\begin{array}{l}\text { Maturidade fisiológica, pontos } \\
\text { Physiologic maturity, points }\end{array}$ & 13,57 & 0,24 & 13,38 & 0,23 & 4,87 & 0,573 \\
\hline $\begin{array}{l}\text { Cor }^{\mathrm{a}} \\
\text { Meat color }\end{array}$ & 2,85 & 0,48 & 4,37 & 0,45 & 34,44 & 0,037 \\
\hline $\begin{array}{l}\text { Textura }^{\mathrm{b}} \\
\text { Texture }^{b}\end{array}$ & 3,85 & 0,38 & 4,50 & 0,35 & 23,68 & 0,234 \\
\hline $\begin{array}{l}\text { Marmoreio }^{c} \\
\text { Marbling }^{c}\end{array}$ & 3,28 & 0,97 & 6,00 & 0,91 & 54,16 & 0,062 \\
\hline $\begin{array}{l}\text { PH da carcaça fria } \\
\text { Cold carcass } p H\end{array}$ & 6,21 & 0,13 & 5,51 & 0,12 & 5,73 & 0,001 \\
\hline $\begin{array}{l}\text { Músculo (\%) } \\
\text { Muscle (\%) }\end{array}$ & 65,38 & 0,99 & 60,48 & 0,93 & 4,18 & 0,003 \\
\hline $\begin{array}{l}\text { Gordura }(\%) \\
\text { Fat }(\%)\end{array}$ & 19,89 & 0,87 & 24,89 & 0,81 & 10,20 & 0,001 \\
\hline $\begin{array}{l}\text { Osso }(\%) \\
\text { Bone }(\%)\end{array}$ & 15,09 & 0,31 & 14,84 & 0,29 & 5,48 & 0,577 \\
\hline $\begin{array}{l}\text { Relação músculo/osso } \\
\text { Muscle/bone relation }\end{array}$ & 4,34 & 0,13 & 4,08 & 0,12 & 8,08 & 0,166 \\
\hline $\begin{array}{l}\text { Relação músc.+gord./osso } \\
\text { Muscle+fat/bone relation }\end{array}$ & 5,66 & 0,15 & 5,77 & 0,14 & 6,78 & 0,619 \\
\hline
\end{tabular}

1 Coeficiente de variação.

a Variação de 1 a 5 , sendo: 1 = escura, 3 = vermelha levemente escura, $5=$ vermelha viva.

b Variação de 1 a 5 , sendo: 1 = muito grosseira, 5 = muito fina.

c Variação de 1 a 18 , sendo: 1-3 = traços, 4-6 leve.

1 Coefficient of variation.

a Variation from 1 to 5 , being: $1=$ dark, $3=$ slightly dark red, $5=$ bright red.

b Variation from 1 to 5 , being: $1=$ very coarse, $5=$ very fine.

c Variation from 1 to 18 , being: 1-3 = traces, 4-6 = slight

ao descongelamento $(\mathrm{r}=-0,30 ; \mathrm{P}>0,476)$, quando foram considerados somente os animais $\mathrm{C}$ (Tabela 5).

Nos animais C, somente o marmoreio esteve correlacionado significativamente com a maciez da carne, sendo $\mathrm{r}=0,82(\mathrm{P}<0,01)$. Também foi significativa $(\mathrm{P}<0,10)$ a correlação entre marmoreio e valor de Shear, sendo $r=-0,62$. Em seu trabalho, MULLER e ROBAINA (1981) verificaram valor de $r=-0,56$, entre essas duas características.

Outra possível explicação para a maior maciez da carne de animais I, no presente trabalho, é relatada por GERRARD et al. (1987), que, em seu estudo, verificaram interação entre idade ao abate e estado sexual influenciando na maciez da carne. No trabalho de GERRARD et al. (1987), constata-se que os animais $C$ apresentaram decréscimo contínuo na maciez da carne, com o incremento da idade, enquanto nos animais I houve grandes oscilações com o incre- mento da idade, com menores valores de Shear aos 12 e 18 meses de idade. Para esses autores, a grande variabilidade ocorrida nos I pode ser atribuída ao rápido ciclo de crescimento como causa do incremento da síntese e degradação rápida do colágeno, que pode estar imaturo e passar por diferentes incrementos na maturação em tempos de amostragem distintos, o que acarretaria as variações observadas na maciez da carne dos animais I.

O teor de colágeno total do músculo em que foram feitas as avaliações de maciez, tanto pelo painel como pelo aparelho WB Shear, mostrou que não existiu diferença significativa entre os dois estados sexuais, sendo os valores de 2,39 e 2,73 mg/g de Longissimus dorsi, respectivamente, nos animais I e C. Em seu trabalho, BURSON et al. (1986) utilizaram animais da raça Simental, abatidos aos 17 meses de idade e não verificaram diferença entre I e C no teor de 
Tabela 3 - Média e erro-padrão (EP) para perda ao descongelamento e à cocção, maciez, platabilidade, suculência, força para corte das fibras (WBS) e teor de colágeno no músculo Longissimus dorsi, de machos Hereford, inteiros ou castrados, abatidos aos quatorze meses

Table 3 - Mean and standard error (SE) for thawing loss, cooking loss, tenderness, palatability, juiciness, Shear and total collagen in the longissimus muscle, of Hereford males, bulls or castrated, slaughtered at fourteen months

\begin{tabular}{|c|c|c|c|c|c|c|}
\hline \multirow[t]{2}{*}{$\begin{array}{l}\text { Característica } \\
\text { Characteristic }\end{array}$} & \multicolumn{2}{|c|}{$\begin{array}{c}\text { Inteiros } \\
\text { Bulls }\end{array}$} & \multicolumn{2}{|c|}{$\begin{array}{c}\text { Castrados } \\
\text { Castrated }\end{array}$} & \multirow[t]{2}{*}{$\mathrm{CV}(\%)^{1}$} & \multirow[t]{2}{*}{$\begin{array}{c}\text { Probabilidade } \\
\text { Probability }\end{array}$} \\
\hline & $\begin{array}{l}\text { Média } \\
\text { Mean }\end{array}$ & $\begin{array}{l}\mathrm{EP} \\
S E\end{array}$ & $\begin{array}{l}\text { Média } \\
\text { Mean }\end{array}$ & $\begin{array}{l}\mathrm{EP} \\
S E\end{array}$ & & \\
\hline $\begin{array}{l}\text { Perda ao descongelamento, } \% \\
\text { Thawing loss, } \%\end{array}$ & 3,29 & 0,81 & 7,48 & 0,75 & 39,90 & 0,001 \\
\hline $\begin{array}{l}\text { Perda à cocção, } \% \\
\text { Cooking loss, \% }\end{array}$ & 23,32 & 1,76 & 28,74 & 1,65 & 17,61 & 0,062 \\
\hline $\begin{array}{l}\text { Maciez, pts } \\
\text { Tenderness, } \text { pts }^{2}\end{array}$ & 7,93 & 0,43 & 6,60 & 0,40 & 15,80 & 0,043 \\
\hline $\begin{array}{l}\text { Suculência, pts }{ }^{2} \\
\text { Juiciness, pts }\end{array}$ & 6,09 & 0,51 & 5,04 & 0,47 & 24,17 & 0,152 \\
\hline $\begin{array}{l}\text { Palatabilidade, } \text { pts }^{2} \\
{\text { Palatability, } p t s^{2}}\end{array}$ & 6,40 & 0,28 & 5,52 & 0,26 & 12,53 & 0,038 \\
\hline $\begin{array}{l}\text { WBS, } \mathrm{kgf} / \mathrm{cm}^{3} \\
\text { Shear, } \mathrm{kgf} / \mathrm{cm}^{3}\end{array}$ & 4,56 & 0,63 & 6,12 & 0,59 & 30,86 & 0,092 \\
\hline $\begin{array}{l}\text { Colágeno, } \mathrm{mg} / \mathrm{g} \text { músculo } \\
\text { Total collagen, } \mathrm{mg} / \mathrm{g} \text { muscle }\end{array}$ & 2,39 & 0,28 & 2,73 & 0,26 & 28,45 & 0,382 \\
\hline
\end{tabular}

${ }^{1}$ Coeficiente de variação.

2 Variação de 1 a 9 , sendo: 1 = sem suculência, sem sabor, extremamente dura; 9 = extremamente suculenta, extremamente saborosa, extremamente macia.

1 Coefficient of variation.

${ }^{2}$ Variation from 1 to 9, being: 1 = extremely tough, extremely dry, extremely undesirable; 9 = extremely tender, extremely juicy, extremely flavorful.

Tabela 4 - Coeficiente de correlação entre as variáveis de machos Hereford inteiros, abatidos aos quatorze meses

Table 4 - Correlation coefficient among variables of meat from Hereford bulls, slaughtered at fourteen months

\begin{tabular}{|c|c|c|c|c|c|c|c|c|c|c|c|}
\hline $\begin{array}{l}\text { Variáveis } \\
\text { Variables }\end{array}$ & Cor $^{1}$ & $\mathrm{Tex}^{2}$ & $\operatorname{Mar}^{3}$ & $\mathrm{PMu}^{4}$ & $\mathrm{PGo}^{5}$ & $\mathrm{PDe}^{6}$ & $\mathrm{PCo}^{7}$ & $\mathrm{Mac}^{8}$ & $\mathrm{Suc}^{9}$ & $\mathrm{Pal}^{10}$ & $\mathrm{WBS}^{11}$ \\
\hline $\operatorname{Tex}^{2}$ & $-0,10$ & & & & & & & & & & \\
\hline $\mathrm{Mar}^{3}$ & 0,04 & $-0,31$ & & & & & & & & & \\
\hline $\mathrm{PMu}^{4}$ & 0,59 & $-0,73^{+}$ & 0,15 & & & & & & & & \\
\hline $\mathrm{PGo}^{5}$ & $-0,32$ & $0,84 *$ & $-0,05$ & $-0,89 * *$ & & & & & & & \\
\hline $\mathrm{PDe}^{6}$ & $0,90 * *$ & $-0,15$ & $-0,07$ & $0,70^{+}$ & $-0,49$ & & & & & & \\
\hline $\mathrm{PCo}^{7}$ & $0,73^{+}$ & $-0,47$ & 0,36 & $0,69^{+}$ & $-0,62$ & $0,82 *$ & & & & & \\
\hline $\mathrm{Mac}^{8}$ & $-0,93 * *$ & 0,13 & 0,24 & $-0,59$ & 0,44 & $-0,88 * *$ & $-0,65$ & & & & \\
\hline Suc $^{9}$ & $-0,72^{+}$ & 0,39 & $-0,41$ & $-0,67^{+}$ & 0,54 & $-0,58$ & $-0,62$ & $0,67^{+}$ & & & \\
\hline $\mathrm{Pal}^{10}$ & $-0,25$ & $0,68^{+}$ & $-0,68^{+}$ & $-0,56$ & 0,62 & $-0,36$ & $-0,81 *$ & 0,13 & 0,44 & & \\
\hline $\mathrm{WBS}^{11}$ & $0,94 * *$ & $-0,18$ & $-0,21$ & $0,68^{+}$ & $-0,45$ & $0,94 * *$ & $0,70^{+}$ & $-0,94 * *$ & $-0,54$ & $-0,20$ & \\
\hline $\mathrm{Col}^{12}$ & 0,40 & $-0,75^{*}$ & $-0,23$ & $0,81 *$ & $-0,90 * *$ & 0,58 & 0,61 & $-0,56$ & $-0,32$ & $-0,47$ & 0,6 \\
\hline
\end{tabular}

** $P<0,01 ;{ }^{*} P<0,05 ;{ }^{+} P<0,10$.

1 cor; ${ }^{2}$ textura; ${ }^{3}$ marmoreio; ${ }^{4}$ percentagem de músculo; ${ }^{5}$ percentagem de gordura; 6 perda ao descongelamento; 7 perda à cocção; ${ }^{8}$ maciez; ${ }^{9}$ suculência; ${ }^{10}$ palatabilidade; ${ }^{11}$ força para corte das fibras; ${ }^{12}$ teor de colágeno total da carne.

** $P<.01 ;{ }^{*} P<.05 ;+P<.10$.

1 meat color ; ${ }^{2}$ texture; ${ }^{3}$ marbling; ${ }^{4}$ muscle percentage; ${ }^{5}$ fat percentage; 6 thawing loss; ${ }^{7}$ cooking loss; 8 tenderness; ${ }^{9}$ juiciness; 10 flavor;

11 WB-Shear; ${ }^{12}$ total meat collagen. 
1900 Rev. bras. zootec.

colágeno total do músculo Longissimus dorsi, reportando $5,34 \mathrm{mg} / \mathrm{g}$ de colágeno total nos animais I e $5,91 \mathrm{mg} / \mathrm{g}$ nos C. Os valores apresentados por BURSON et al. (1986) foram mais elevados que os do presente trabalho, entretanto, esse autor trabalhou com animais de 17 meses.

Após reconhecer que os principais fatores relacionados à maciez da carne são o teor de colágeno e os complexos de enzimas cálcio-dependentes que fazem a degradação post-mortem das células do músculo, MORGAN et al. (1993) não verificaram diferença na maciez da carne medida pelo painel, mas os animais I apresentaram maiores valores de Shear. Esses mesmos autores comentam que houve menor fragmentação das miofibrilas na carne de animais inteiros associada ao maior nível de inibidor das enzimas cálcio-dependentes (a calpastatina) no músculo de animais I. Entretanto, MORGAN et al. (1993) relataram que, para abate de animais em idade precoce, a utilização de animais I é perfeitamente viável, pois em idades jovens o conteúdo de colágeno insolúvel é reduzido e os níveis de calpastatina não apresentam efeito marcante. Além disso, embora não tenha sido possível medir, no presente estudo, a concentração de calpastatina no músculo, o seu efeito é pequeno quando se trabalha com carcaças que são resfriadas após o abate (WHEELER et al., 1990), como acontece nos frigoríficos brasileiros.

No presente trabalho, no qual o objetivo é estudar a viabilidade da utilização de animais não-castrados para o abate com 14-15 meses, observa-se que, mesmo que os animais I não sofressem o possível efeito do estresse pré-abate, não seria de se esperar diferença na maciez da carne desses animais, pois o nível de colágeno total não diferiu entre os dois estados sexuais.

Observa-se nas Tabelas 4 e 5 que o teor de colágeno esteve significativamente correlacionado com a textura da carne, sendo o $\mathrm{r}=-0,75$ nos animais $\mathrm{I}$ e $r=-0,66$ nos C. Ainda na Tabela 4 , observa-se que nos animais I o teor de colágeno esteve positivamente correlacionado com a percentagem de músculo $(\mathrm{r}=0,81)$ e negativamente correlacionado com o teor de gordura na carcaça $(r=-0,90)$, o que era de se esperar, uma vez que esse tecido envolve as fibras, os feixes de fibras musculares e o próprio músculo, formando, respectivamente, o endomísio, o epimísio e o perimísio.

Ainda na Tabela 3, observa-se que também a palatabilidade da carne foi melhor nos animais I $(\mathrm{P}<0,05)$. A melhor palatabilidade da carne dos animais inteiros atribuída pelo painel de degustadores pode ser em função da maior maciez desta quando comparada a carne dos animais C. Dos fatores que influenciam a palatabilidade da carne de animais de mesma raça, mesma idade e submetidos às mesmas condições alimentares, observa-se que o marmoreio esteve negativamente correlacionado $(\mathrm{P}<0,10) \mathrm{com}$ a palatabilidade da carne nos animais I (Tabela 4). Nos C, embora positiva, a correlação entre essas duas variáveis não foi significativa $(r=40 ; P>0,10)$, mostrando que não houve influência definida do marmoreio sobre a palatabilidade. VAZ (1999) relatou que a palatabilidade da carne esteve melhor correlacionada com a maciez $(r=0,40)$ do que com o marmoreio $(r=0,21)$.

Tabela 5 - Coeficiente de correlação entre as variáveis de machos Hereford castrados, abatidos aos 14 meses Table 5 - Correlation coefficient among variables of meat from Hereford castrated males, slaughtered at 14 months

\begin{tabular}{|c|c|c|c|c|c|c|c|c|c|c|c|}
\hline $\begin{array}{l}\text { Variáveis } \\
\text { Variables }\end{array}$ & Cor $^{1}$ & $\mathrm{Tex}^{2}$ & $\mathrm{Mar}^{3}$ & $\mathrm{PMu}^{4}$ & $\mathrm{PGo}^{5}$ & $\mathrm{PDe}^{6}$ & $\mathrm{PCo}^{7}$ & $\mathrm{Mac}^{8}$ & Suc $^{9}$ & $\mathrm{Pal}^{10}$ & $\mathrm{WBS}^{11}$ \\
\hline $\operatorname{Tex}^{2}$ & 0,52 & & & & & & & & & & \\
\hline $\mathrm{Mar}^{3}$ & 0,32 & 0,22 & & & & & & & & & \\
\hline $\mathrm{PMu}^{4}$ & 0,48 & 0,23 & $-0,33$ & & & & & & & & \\
\hline $\mathrm{PGo}^{5}$ & $-0,59$ & $-0,30$ & 0,40 & $-0,92 * *$ & & & & & & & \\
\hline $\mathrm{PDe}^{6}$ & 0,05 & 0,28 & $-0,16$ & $-0,16$ & 0,08 & & & & & & \\
\hline $\mathrm{PCo}^{7}$ & $-0,05$ & $-0,02$ & $-0,01$ & 0,12 & $-0,17$ & 0,01 & & & & & \\
\hline $\mathrm{Mac}^{8}$ & 0,47 & 0,45 & $0,82 * *$ & 0,20 & $-0,09$ & $-0,30$ & 0,24 & & & & \\
\hline $\mathrm{Suc}^{9}$ & 0,45 & $0,84 * *$ & 0,22 & 0,22 & $-0,14$ & 0,24 & $-0,08$ & 0,39 & & & \\
\hline $\mathrm{Pal}^{10}$ & 0,17 & 0,25 & 0,44 & 0,06 & 0,18 & $-0,15$ & 0,23 & 0,52 & $0,65^{+}$ & & \\
\hline $\mathrm{WBS}^{11}$ & $-0,64 *$ & 0,01 & $-0,67 *$ & $-0,05$ & 0,10 & 0,24 & 0,24 & $-0,54$ & 0,13 & 0,07 & \\
\hline $\mathrm{Col}^{12}$ & $-0,67^{+}$ & $-0,66^{+}$ & 0,06 & $-0,46$ & 0,50 & $-0,65$ & 0,13 & $-0,10$ & $-0,65^{+}$ & $-0,11$ & 0,09 \\
\hline
\end{tabular}


Já com relação à suculência (Tabela 3), observa-se que a maior quebra ao descongelamento da carne dos animais $C$ não foi suficiente para influenciar significativamente $(\mathrm{P}>0,152)$ a suculência da carne, como ocorreu em outros estudos (VAZ et al., 1999a; VAZ, 1999). No presente trabalho, a suculência da carne nos animais I foi classificada como "levemente acima da média"( 6,09 pontos)e nos $C$, como “média"( 5,04 pontos).

\section{Conclusões}

Animais inteiros abatidos aos 14 meses de idade apresentaram carcaças com maior teor de músculo e menor quantidade de gordura do que os castrados.

Não existiu diferença na suculência da carne de animais inteiros em relação aos castrados, quando o abate ocorreu aos 14 meses.

O maior estresse pré-abate em animais inteiros pode resultar em carne mais macia e mais escura.

\section{Referências Bibliográficas}

BURSON, D.E., HUNT, M.C., UNRUH, J.A., et al. 1986. Proportion of types I and III collagen in Longissimus collagen from bulls and steers. J. Anim. Sci., 63(2):453-456.

DRANSFIELD, E. 1994. Optimisation of tendernisation, ageing and tenderness. Meat Sci., 36(1):105-121.

FELICIO, P.E. Fatores ante e póst-mortem que influenciam na qualidade da carne vermelha. In: SIMPÓSIOS DA REUNIÃO ANUAL SOCIEDADE BRASILEIRA DE ZOOTECNIA, 30, 1993, Rio de Janeiro. Anais... Niterói: SBZ, 1993. p.43-52.

FIELD, R.A. 1971. Effect of castration on meat quality and quantity. J. Anim. Sci., 32(5):849-857.

GERRARD, D.E., JONES, S.J., ABERLE, E.D. et al. 1987. Collagen stability, testosterone secretion and meat tenderness in growing bulls and steers. J. Anim. Sci., 65(5):1236-42.

HEDRICK, H.B., THOMPSON, G.B., KRAUSE, G.F. 1969. Comparison of feedlot performance and carcass characteristics of half-sib bulls, steers and heifers. J. Anim. Sci., 29(3):687-693.

JUDGE, M.D., ABERLE, E.D., FORREST, J.C. et al. 1989. Principles of meat science. Dubuque: Kendall/Hunt. 351p.

LAWRIE, R.A. 1970. Ciência de la carne. Zaragoza: Acribia. 342p.

MORGAN, J.B., WHEELER, T.L., KOOHMARAIE, M. et al. 1993. Effect of castration on myofibrillar protein turnover, endogenous proteinase activities, and muscle growth in bovine skeletal muscle. J. Anim. Sci., 71(2):408-414.

MULLER, L. 1987. Normas para avaliação de carcaças e concurso de carcaça de novilhos. 2.ed. Santa Maria: Imprensa Universitária. 31p.

MULLER, L., RESTLE, J. Carcass characterisitcs of steers and young bulls. In: EUROPEAN CONGRESS OF MEAT RESEARCHER WORKERS, 29, 1983, Parma. Proceedings... Parma: CERCA, 1983. p.530-535.

MULLER, L., ROBAINA, G.P. Qualidade da carne de novilhos de raças britânicas de idade cronológica diferentes. In: REU-
NIÃO ANUAL SOCIEDADE BRASILEIRA DE ZOOTECNIA, 18, 1981, Goiânia. Anais... Goiânia: SBZ, 1981. p.391.

RESTLE, J., BRONDANI, I.L., BERNARDES, R.A.C. 1999a. O novilho superprecoce. In: RESTLE, J. (Ed.) Confinamento, pastagens e suplementação para produção de bovinos de corte. Santa Maria: Imprensa Universitária. p.191-214.

RESTLE, J., BRONDANI, I.L., FLORES, J.L.C. et al. 1997. Desempenho em confinamento, do desmame ao abate aos quatorze meses, de bovinos inteiros ou castrados, produzidos por vacas de dois anos. Ciência Rural, 27(4):651-655.

RESTLE, J., GRASSI, C., FEIJÓ, G.L.D. 1996a. Características das carcaças e da carne de bovinos inteiros ou submetidos a duas formas de castração, em condições de pastagem. R. Soc. Bras. Zootec., 25(2):334-344.

RESTLE, J., GRASSI, C., FEIJÓ, G.L.D. 1994. Características de carcaça de bovinos de corte inteiros ou castrados em diferentes idades. Pesq. Agrop. Bras., 29(10):1603-07.

RESTLE, J., GRASSI, C., FEIJÓ, G.L.D. 1996b. Desenvolvimento e rendimento de carcaça de bovinos inteiros ou submetidos a duas formas de castração, em condições de pastagem. R. Soc. Bras. Zootec., 25(2):324-333.

RESTLE, J., VAZ, F.N., ALVES FILHO, D.C. Machos não-castrados para a produção de carne. In: RESTLE, J. (Ed.) Confinamento, pastagens e suplementação para produção de bovinos de corte. Santa Maria: Imprensa Universitária. p.215-231.

RESTLE, J., VAZ, F.N. 1997. Aspectos quantitativos da carcaça de machos Hereford inteiros ou castrados, abatidos aos quatorze meses. Pesq. Agrop. Bras., 32(10):1091-95.

SEIDEMAN, S.C., CROSS, H.R., OLTJEN, R.R. et al. 1982. Utilization of the intact male for red meat production: a review. J. Anim. Sci., 55(4)826-840.

VAZ, F.N. Cruzamento alternado das raças Charolês e Nelore: características de carcaça e da carne de novilhos abatidos aos dois anos. Santa Maria, RS: UFSM, 1999. 58p. Dissertação (Mestrado em Zootecnia) - Universidade Federal de Santa Maria, 1999.

VAZ, F.N., RESTLE, J., FEIJÓ, G.L.D. 1999a. Qualidade e composição química da carne de bovinos de corte inteiros ou castrados de diferentes composições raciais Charolês x Nelore. Rev. bras. zootec. (No prelo).

VAZ, F.N., ROSO, C., VAZ, R.Z. 1999b. Gerenciamento visando a eficiência econômica da pecuária de corte. In: RESTLE, J. (Ed.) Confinamento, pastagens e suplementação para produção de bovinos de corte. Santa Maria: Imprensa Universitária. p.232-258.

WHEELER, T.L., SAVELL, J.W., CROSS, H.R. et al. 1990. Mechanisms associated with the variation in tenderness of meat from Brahman and Hereford cattle. J. Anim. Sci., 68(12):4206-20.

Recebido em: 02/12/99

Aceito em: 04/04/00 